\title{
Jolkinolide B induces apoptosis in MCF-7 cells through inhibition of the PI3K/Akt/mTOR signaling pathway
}

\author{
HUI-YU XU ${ }^{1,2^{*}}$, ZHI-WEI CHEN ${ }^{1,2^{*}}$, JIN-CAI HOU ${ }^{3}$, FENG-XIA DU ${ }^{1}$ and JI-CHENG LIU ${ }^{3}$ \\ ${ }^{1}$ Department of Immunology, Qiqihar Medical University, Qiqihar, Heilongjiang 161006; \\ ${ }^{2}$ Heilongjiang University of Chinese Medicine, Harbin, Heilongjiang $150040 ;{ }^{3}$ The Institute of \\ Medicine, Qiqihar Medical University, Qiqihar, Heilongjiang 161006, P.R. China
}

Received June 2, 2012; Accepted August 17, 2012

DOI: $10.3892 /$ or.2012.2113

\begin{abstract}
The aim of this study was to explore the molecular mechanisms of jolkinolide B (JB), which is extracted from the root of Euphorbia fischeriana Steud. In this study, we found that $\mathrm{JB}$, a diterpenoid from the traditional Chinese medicinal herb, strongly inhibited the PI3K/Akt/mTOR signaling pathway. Furthermore, we evaluated the effects of JB on the proliferation and apoptosis of MCF-7 human breast cancer cells. Our results showed significant induction of apoptosis in MCF-7 cells incubated with JB. The viability of the MCF-7 cells was assessed by MTT assay. Flow cytometry was used to detect apoptosis and cell cycle analysis. Transmission electron microscopy (TEM) analysis was used to observe cell morphology. MCF-7 cells were subcutaneously inoculated into nude mice to study the in vivo antitumor effects of JB. The growth of MCF-7 cells was inhibited and arrested in the $\mathrm{S}$ phase by JB. The data showed significantly decreased tumor volume and weight in nude mice inoculated with MCF-7 cells. In addition, treatment with JB was able to induce downregulation of cyclinD1, cyclinE, mTOR, p-PI3K and p-Akt, and upregulation of PTEN and p-eIF4E. Collectively, JB-induced apoptosis of MCF-7 cells occurs through the PI3K/Akt/mTOR signaling pathway. Furthermore, the PI3K/Akt signaling cascade plays a role in the induction of apoptosis in JB-treated cells. These observations suggest that JB may have therapeutic applications in the treatment of cancer.
\end{abstract}

Correspondence to: Professor Ji-Cheng Liu, The Institute of Medicine, Qiqihar Medical University, 333 BuKui Street, Jianhua District, Qiqihar, Heilongjiang 161006, P.R. China

E-mail:czwzp@tom.com

${ }^{*}$ Contributed equally

Key words: jolkinolide B, apoptosis, PI3K/Akt/mTOR, MCF-7

\section{Introduction}

Lang-du (LD) is a naturally occurring product from the Traditional Chinese Medicine (TCM) Euphorbia fischeriana Steud. LD has been used in China to treat clinical patients with cancer, edema, and ascites for many years. The discovery of novel natural compounds with low toxicity and high selectivity of killing various cancer cells, including MCF-7 cells, is an important area in cancer research. Due to their wide range of biological activities and low toxicity in animal models, some natural products have been used as alternative treatments for cancer (1).

Jolkinolide B (JB) is a diterpenoid component isolated from the dried roots of Euphorbia fischeriana Steud. It has been reported that $\mathrm{JB}$ regulates proliferation and induces apoptosis in human prostate LNCaP cancer, MDA-MB-231 and K562 cells in vitro (2-4). The purpose of this study was to investigate the effects of $\mathrm{JB}$ on the in vitro and in vivo growth of MCF-7 cells and its molecular mechanisms of action. Our results showed that JB significantly suppressed the in vitro MCF-7 cell growth in a dose- and time-dependent manner. We investigated the induction of apoptosis in MCF-7 breast cancer cells and examined whether its effects are associated with the $\mathrm{PI} 3 \mathrm{~K} / \mathrm{Akt} / \mathrm{mTOR}$ signaling pathway. Apoptosis is associated with biochemical changes mediated by various genes and cell signaling pathways, such as the phosphoinositide 3-kinase (PI3K)/Akt survival pathway.

\section{Materials and methods}

Plant extracts and purification. JB (molecular weight of $330.4 \mathrm{kDa}$, chemical formula $\mathrm{C}_{28} \mathrm{H}_{26} \mathrm{O}_{4}$, purity >99\%) (Fig. 1) was kindly provided by Professor Shujun Zhang (Chemical Engineering Institute, Qiqihar University). JB was dissolved in dimethylsulfoxide (DMSO) to make a stock solution at a concentration of $100 \mathrm{mM}$, which was further diluted to the appropriate concentration with culture medium prior to each experiment. Control experiments contained DMSO.

Cell line and cell culture. The human breast cancer cell line MCF-7 was obtained from the Laboratory of Molecular Oncology, Beijing Cancer Hospital/Institute. Cells were incubated in complete DMEM (Gibco BRL; Grand Island, NY, 
USA) supplemented with 5\% heat-inactivated fetal bovine serum (FBS; Gibco BRL) in a humidified atmosphere at $37^{\circ} \mathrm{C}$ and $5 \% \mathrm{CO}_{2}$.

Cell viability analysis. Cells $\left(1 \times 10^{4} / \mathrm{ml}\right)$ were cultured in 96-well chamber slides for $24 \mathrm{~h}$ prior to use in the experiment. Culture medium was replaced with fresh medium containing the appropriate concentration of JB ranging from 0 to $80 \mu \mathrm{g} / \mathrm{ml}$, and fresh medium with the drug was added from 24 to $72 \mathrm{~h}$. MTT (Sigma-Aldrich; St. Louis, MO, USA) was added into each well and cultured for another $4 \mathrm{~h}$, and the supernatant was discarded and supplemented with $100 \mu 1$ DMSO. When the crystals were dissolved, the absorbance values were read on the enzyme-labeled mini reader II (Bio-Rad; Hercules, CA, USA) at the wave length of $570 \mathrm{~nm}$. The procedure was repeated three times.

Cell cycle analysis. Cells were seeded in 60-mm culture dishes and grown to $50 \%$ confluence. Subsequently, the cells were cultured in serum-free medium for $24 \mathrm{~h}$ and then incubated with $0,10,20,40 \mu \mathrm{g} / \mathrm{ml}$ of JB for $24 \mathrm{~h}$ in complete medium. The cells were harvested by trypsinization, centrifuged at 2,000 rpm for $5 \mathrm{~min}$, washed in PBS, and resuspended in cold $70 \%$ ethanol. Finally, $1 \mathrm{ml}$ propidium iodide stain solution $(20 \mu \mathrm{g} / \mathrm{ml}$ PI, $100 \mu \mathrm{g} / \mathrm{ml}$ DNase free RNase A) was added to the samples which were analyzed on a FACScan (BectonDickinson; San Francisco, CA, USA) within 30 min. Data on 20,000 cells were acquired and processed using Lysis II software (Becton-Dickinson).

Flow cytometric analysis of apoptosis. Cells were seeded in 6 -well plates at a density of $1.2 \times 10^{6}$ cells/well. After $24 \mathrm{~h}$ of JB treatment at a concentration of $0,10,20,40 \mu \mathrm{g} / \mathrm{ml}$, cells were collected, washed twice with cold PBS and $1 \times 10^{6}$ cells were resuspended in $500 \mathrm{ml} 1 \mathrm{X}$ binding buffer. Subsequently, $100 \mu 1$ of cell suspension was transferred to a $5 \mathrm{ml}$ culture tube and incubated with $10 \mu \mathrm{l}$ of Annexin $\mathrm{V}$ antibodies and $10 \mu \mathrm{l}$ of propidium iodide containing $300 \mu \mathrm{g} / \mathrm{ml}$ RNase (Sigma). The cells were vortexed gently and incubated for $15 \mathrm{~min}$ at room temperature (RT) in the dark. $1 \mathrm{X}$ binding buffer $(400 \mu \mathrm{l})$ was added to each tube and the cells were analyzed with flow cytometry within $1 \mathrm{~h}$.

Transmission electron microscopy (TEM) analysis. In brief, small sections of tumor tissue $\left(1 \mathrm{~mm}^{3}\right)$ from control and treated mice were fixed with $4 \%$ paraformaldehyde and $2 \%$ glutaraldehyde in $0.1 \mathrm{M}$ sodium phosphate buffer ( $\mathrm{pH}$ 7.4) for $4 \mathrm{~h}$ at RT $\left(24^{\circ} \mathrm{C}\right)$. This was followed by washing the tissue samples in $0.1 \mathrm{M}$ sodium phosphate buffer ( $\mathrm{pH}$ 7.4) and then placing them in $2 \%$ osmium tetroxide in $0.1 \mathrm{M}$ sodium phosphate buffer (pH 7.4) for $2 \mathrm{~h}$ at room temperature. Dehydration was carried out in an ascending grade of ethanol, followed by embedding in Epon 812 and polymerization at $60^{\circ} \mathrm{C}$ for $48 \mathrm{~h}$. Ultrathin sections $(50-70 \mathrm{~nm})$ were obtained using an Ultracut Ultra microtome (Leica Microsystems GmbH; Wetzlar, Germany) and picked up onto 200-mesh copper grids. The sections were double-stained with uranyl acetate and lead citrate and then analyzed under an FEI Tecnai-12 twin transmission electron microscope equipped with an SIS Mega View II CCD camera at $80 \mathrm{kV}$ (FEI Co.; Hillsboro, OR, USA).

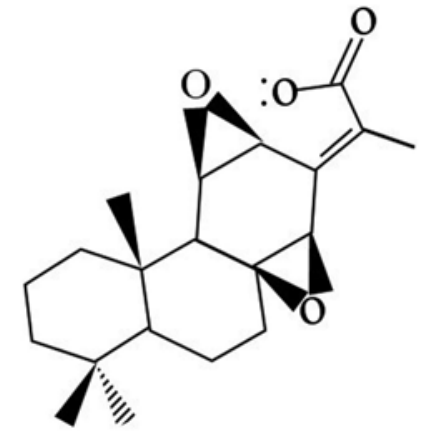

Figure 1. Chemical structure of jolkinolide B.

Western blot analysis. Western blot analysis was performed as previously described. Proteins were transferred to a nitrocellulose membrane and blots were probed with anticyclinD1, cyclinE, p-PI3K, p-Akt, PTEN, mTOR, p-eIF4E and $\beta$-actin followed by incubation with horseradish peroxidaseconjugated mouse or rabbit immunoglobulin. Blots were then developed using the West Pico Chemiluminescent substrate (Pierce; Woburn, MA, USA).

Xenograft tumor in nude mice. All animal procedures were approved by the Committee on Animal Experimentation of Beijing Cancer Hospital and the procedures complied with the NIH Guide for the Care and Use of Laboratory Animals. Female Balb/c nude mice (4-5 weeks of age), obtained from the Beijing Vital River Experimental Animals Technology (Beijing, China), were used in all experiments. Suspensions of $5 \times 10^{5}$ cells for MCF-7 in $100 \mu \mathrm{l}$ PBS were subcutaneously inoculated into the right and left flank of the nude mice $(n=3$ in each group). JB ( $40 \mathrm{mg} / \mathrm{kg}$ ) was administered intraperitoneally every three days for one month. Tumor growth was measured with a caliper every three days using the formula, tumor volume $\mathrm{V}\left(\mathrm{mm}^{3}\right)$ = height $\mathrm{x}$ length $\mathrm{x}$ depth. All of the nude mice were fed for one month. At the end of the experiment, tumor tissues were weighed and harvested for additional analyses as described below.

Immunocytochemistry. All tumor tissues were fixed with $4 \%$ paraformaldehyde ( $\mathrm{pH}$ 7.4) and embedded in paraffin. All were plated on coverslips and fixed with cold acetone for 10 min. Following washing with PBS, coverslips were treated with methanol-hydrogen peroxide $(97 \mathrm{ml}: 3 \mathrm{ml})$ for $30 \mathrm{~min}$ at RT. All coverslips were washed in PBS and treated with 1:100 dilution of antibody (p-PI3K, p-Akt, PTEN, mTOR, IgG conjugated with HRP) for $1 \mathrm{~h}$ at $37^{\circ} \mathrm{C}$. Coverslips were washed thoroughly and treated with $0.05 \%$ DBA containing $0.05 \%$ fresh hydrogen peroxide. Coverslips were counter-stained with haematoxylin and observed under a light microscope.

Statistical analysis. Each experiment was performed at least three times. All data were expressed as the mean value \pm standard deviation (SD). The means of the different groups were compared using one-way of variance (ANOVA). All statistical analyses were performed with the SPSS17.0 software (SPSS; Chicago, IL, USA). Differences were considered statistically significant at $\mathrm{p}<0.05, \mathrm{p}<0.01, \mathrm{p}<0.001 . \log \mathrm{IC}_{50}$ calculation was performed using the built-in algorithms for dose-response 

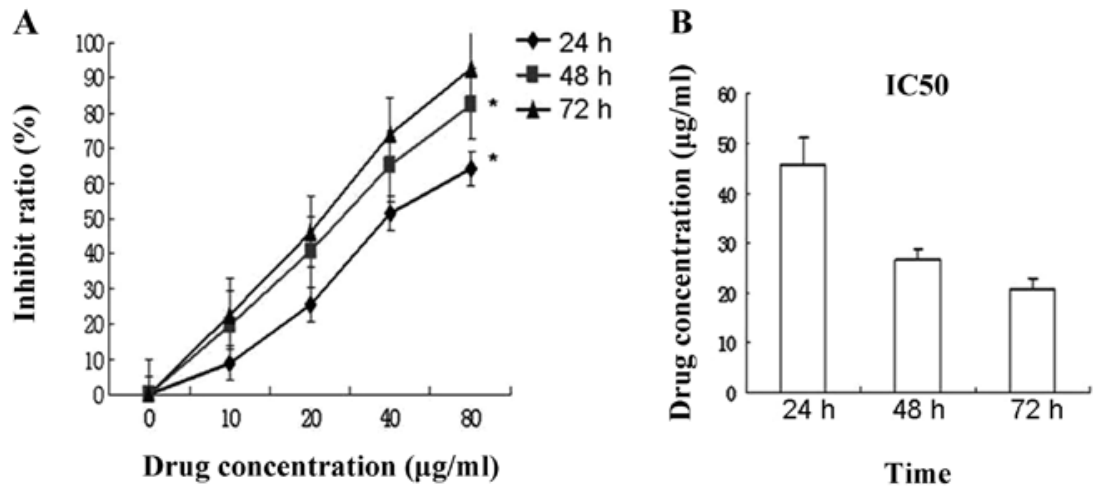

Figure 2. Functional studies of JB in MCF-7 cells. (A) Growth curves of MCF-7 cells treated with JB, as determined by MTT assay. Growth inhibition of MCF-7 cells was directly proportional to the absorbance at a wavelength of $570 \mathrm{~nm}$. Cell survival showed a time-and dose-dependent manner. Error bars represent the standard error of the mean (SEM) ("P<0.05). (B) $\mathrm{IC}_{50}$ (treatment with different drug concentrations of JB) was measured by MTT analysis in a dose-dependent manner.

A
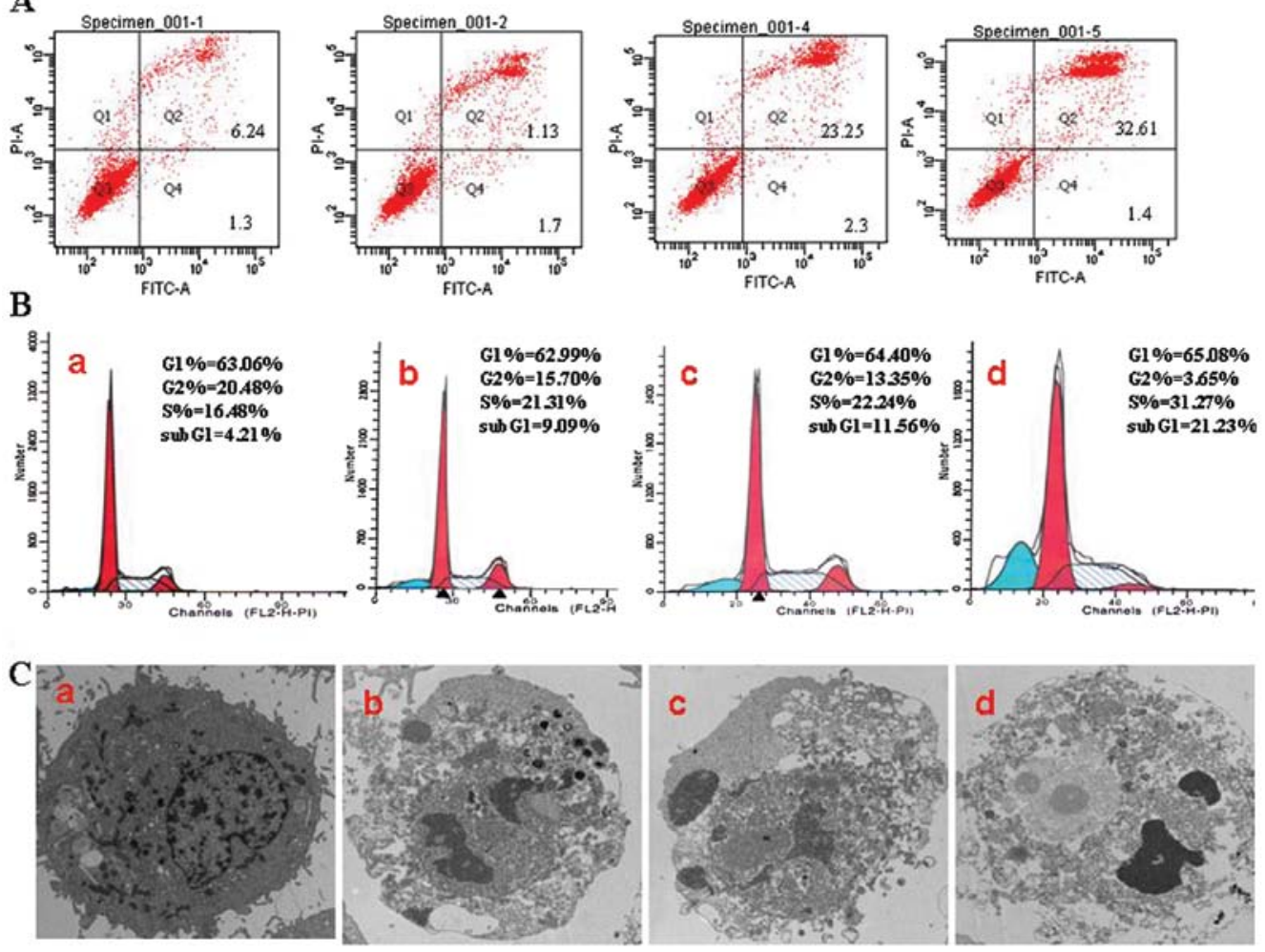

Figure 3. JB induces $\mathrm{S}$ arrest and apoptosis in vitro. (A) Flow cytometry data indicate $\mathrm{S}$ arrest in BGC 823 cells after incubation with JB for $24 \mathrm{~h}$. (B) a, JB $0 \mu \mathrm{g} / \mathrm{ml}$; b, JB $10 \mu \mathrm{g} / \mathrm{ml} ; \mathrm{c}$, JB $20 \mu \mathrm{g} / \mathrm{ml}$; d, JB $40 \mu \mathrm{g} / \mathrm{ml}$. Staining and Annexin V/PI dual-immunofluorescence staining (treatment with JB for $24 \mathrm{~h}$ ) revealed that the drug increased significantly the cells of apoptosis and necrosis (measured as Annexin V+/PI+ cells). (C) Transmission electron microscope showed different changes in the four groups. a, JB $0 \mu \mathrm{g} / \mathrm{ml} ; \mathrm{b}, \mathrm{JB} 10 \mu \mathrm{g} / \mathrm{ml}$; c, JB $20 \mu \mathrm{g} / \mathrm{ml} ; \mathrm{d}, \mathrm{JB} 40 \mu \mathrm{g} / \mathrm{ml}$.

curve with variable slope. A fixed maximum value of the dose-response curve was set to maximum obtained value for each drug.

\section{Results}

Effect of $J B$ on the proliferation of MCF-7 cells. Cell viability was measured by MTT analysis. The treatment of MCF-7 cells for $24-72 \mathrm{~h}$ with $0-80 \mu \mathrm{g} / \mathrm{ml}$ resulted in a dose-dependent decrease in cell proliferation (Fig. 2A). Following treatment with the different concentrations of JB for 24,48 , and $72 \mathrm{~h}$, the growth activities of drug treatment groups were reduced in a time-dependent manner by $\mathrm{IC}_{50}$ (Fig. 2B), $(\mathrm{p}<0.05, \mathrm{p}<0.01)$.

$J B$ causes apoptosis and induces $S$ arrest in MCF-7 cells. The percentages of G1, S, and G2/M cells were evaluated by PI staining and flow cytometric analysis. The apoptotic rates (APO) of the experimental groups $(9.09 \pm 1.13 \%$ and $11.56 \pm 2.25 \%)$ were higher than those of the untreated control group $(4.21 \pm 0.54 \%)$. Together with the prolongation of time, the experimental group of JB $(40 \mu \mathrm{g} / \mathrm{ml})$ showed typical apoptosis peak $(21.23 \pm 4.25 \%)$. Meanwhile, the cell cycle also showed 

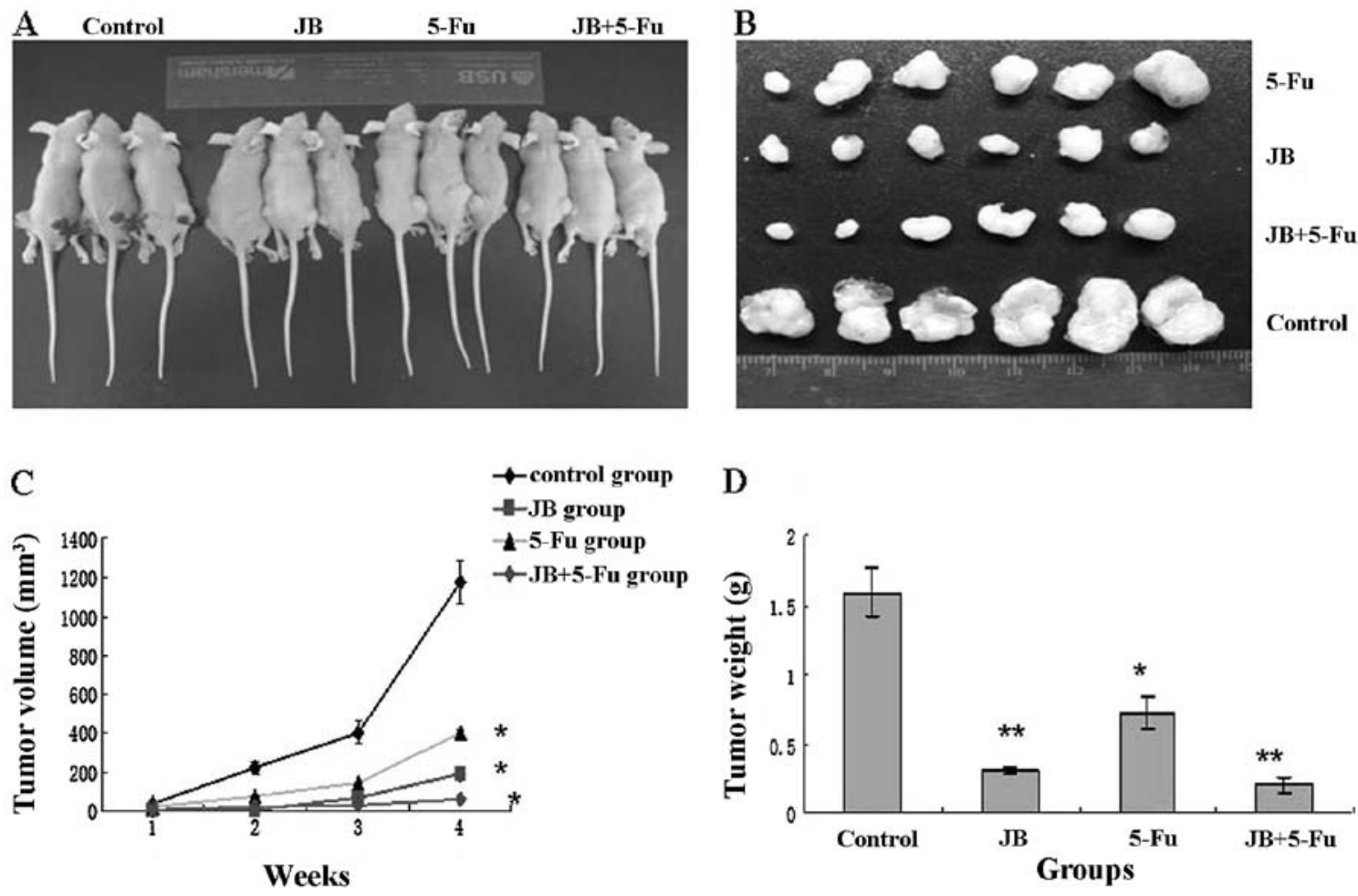

Figure 4. Antitumor effect of JB on nude mice bearing MCF-7 cells subcutaneously was studied in vivo. (A) The groups of nude mice. (B) Dissected tumor tissues from the nude mice. The six tumor tissues derived from the JB (40 mg/kg) group were smaller than the six tumor tissues from the control group. There was a statistical difference between the JB and the control group. (C) The nude mice were administered JB via intraperitoneal injection every 3 days. Tumor volume was measured once every 3 days. (D) The results of tumor weight were consistent with the results of tumor volume. Error bars represent the standard error of the mean (SEM). ( $\mathrm{P}<0.05$ vs. control group). All results were expressed as mean \pm SEM.

notable change with the appearance of $S$ peak and increased percentage of S cells (Fig. 3B). When cells were treated with $40 \mu \mathrm{g} / \mathrm{ml} \mathrm{JB}$ for $24 \mathrm{~h}$, we found a significant number of cells that was more prominently arrested at the $\mathrm{S}$ phase of the cell cycle $(31.27 \pm 3.91 \%)$ than in the JB $0 \mu \mathrm{g} / \mathrm{ml}$ group $(16.48 \pm 1.7 \%)$ (Fig. 3B) Furthermore, we performed phosphatidylserine externalization (Annexin $\mathrm{V}$ binding) and cell membrane integrity (PI staining) binding assay to detect the redistribution of phosphatidylserine, which is a hallmark for early apoptotic cells.

Annexin V-FITC/PI dual labeling further showed that after treatment with $\mathrm{JB}(10,20$ and $40 \mu \mathrm{g} / \mathrm{ml}$ for $24 \mathrm{~h})$, the maximum concentration of JB induced a higher percentage of apoptosis cells; JB $40 \mu \mathrm{g} / \mathrm{ml}(32.61 \pm 5.87 \%)$ compared to JB $0 \mu \mathrm{g} / \mathrm{ml}$ $(6.24 \pm 1.24 \%)$ (Fig. 3A). The representative morphological changes in MCF-7 cell were observed by transmission electron microscope (original magnification, $\mathrm{x} 10,000$ ). The JB $0 \mu \mathrm{g} / \mathrm{ml}$ group of cells cultured membrane showed normal, the nuclei were round and homogeneous, the structure displayed after staining. With the increasing concentration of JB, apoptotic cells appeared more and more in the JB-treated group. The typical characteristics of apoptosis were cytoplasmic edema and nuclei condensed, the fragmented chromatin arranged against the nuclear membrane when MCF-7 cells were treated with JB $(10,20,40 \mu \mathrm{g} / \mathrm{ml})$ for $24 \mathrm{~h}$. The JB $40 \mu \mathrm{g} / \mathrm{ml}$ group of cells presented necrosis (Fig. 3C).

$J B$ inhibits tumor growth in nude mice. To confirm the antitumor effect of JB in vivo, MCF-7 cells were transplanted into nude mice. There was no statistical difference between the four groups at the start of treatment $(\mathrm{P}>0.05)$, and they were randomly divided into four groups: the negative control group, the JB group (40 mg/kg), the $5-\mathrm{Fu}$ group $(5 \mathrm{mg} / \mathrm{kg}$ ), and the $\mathrm{JB}+5-\mathrm{Fu}$ group. Tumor growth curves were depicted (Fig. 4C) to compare the differences in the antitumor efficacy during the course of the experiments. At 28 days, tumor volume in the $5-\mathrm{Fu}$, the $5-\mathrm{Fu}+\mathrm{JB}$ and the JB group were greatly reduced, while tumors in the control group reached $1,207 \mathrm{~mm}^{3}$. The differences in the tumor sizes of the four groups was significant $(\mathrm{P}<0.05)$; however, no significant difference was observed between the $\mathrm{JB}$ and the $\mathrm{JB}+5-\mathrm{Fu}$ group $(\mathrm{P}>0.05)$. The results of tumor weight were consistent with the results of tumor volume $(\mathrm{P}<0.05$ vs. control group, $\mathrm{P}<0.01$ vs. control group) (Fig. 4D).

$J B$ induces tumor tissue apoptosis in vivo. The transplanted tumor tissues were dispersed into single cells for analysis by flow cytometry. Fig. 5B shows that tumor tissues from the $5-\mathrm{Fu}$, the $\mathrm{JB}$ and the $\mathrm{JB}+5-\mathrm{Fu}$ group presented notable changes with increased percentage of $\mathrm{S}$ cells and decreased percentage of $\mathrm{G} 2 / \mathrm{M}$ cells. The apoptotic rate in the $\mathrm{JB}+5-\mathrm{Fu}$ group $(31.26 \pm 3.15 \%)$ was higher than that in the control group $(4.24 \pm 1.25 \%)$. Annexin V-FITC/PI dual labeling further showed that treatment with JB induced a higher percentage of apoptosic cells in the JB $40 \mathrm{mg} / \mathrm{mg}+5-\mathrm{Fu} 5 \mathrm{mg} / \mathrm{mg}$ $(31.26 \pm 6.24 \%)$ than in the control group $(4.24 \pm 2.19 \%)(\mathrm{P}<0.05)$ (Fig. 5A). Fig. 5C shows cellular morphology by TEM. The JB group showed that the nuclear DNA of apoptotic cells displayed nucleus pyknosis and distortion, chromatin condensation, margination, and fracture. 
A

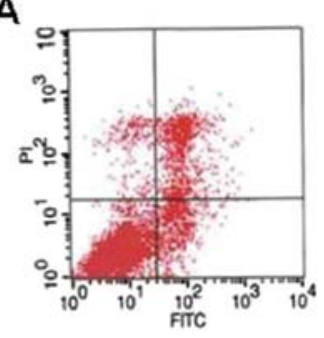

B

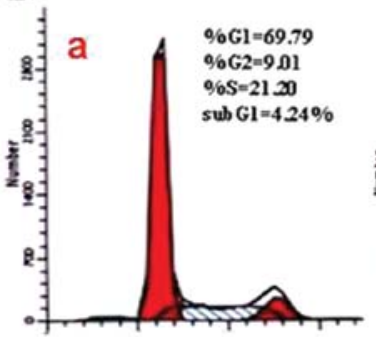

$\mathrm{C}$

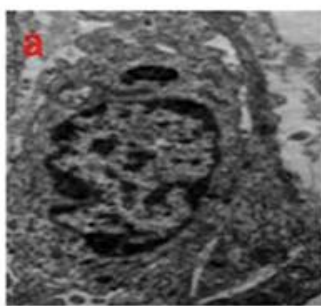

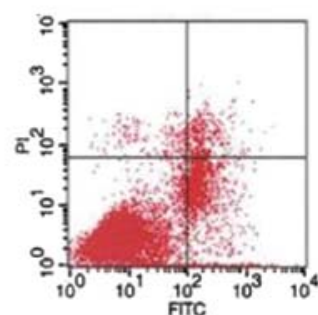
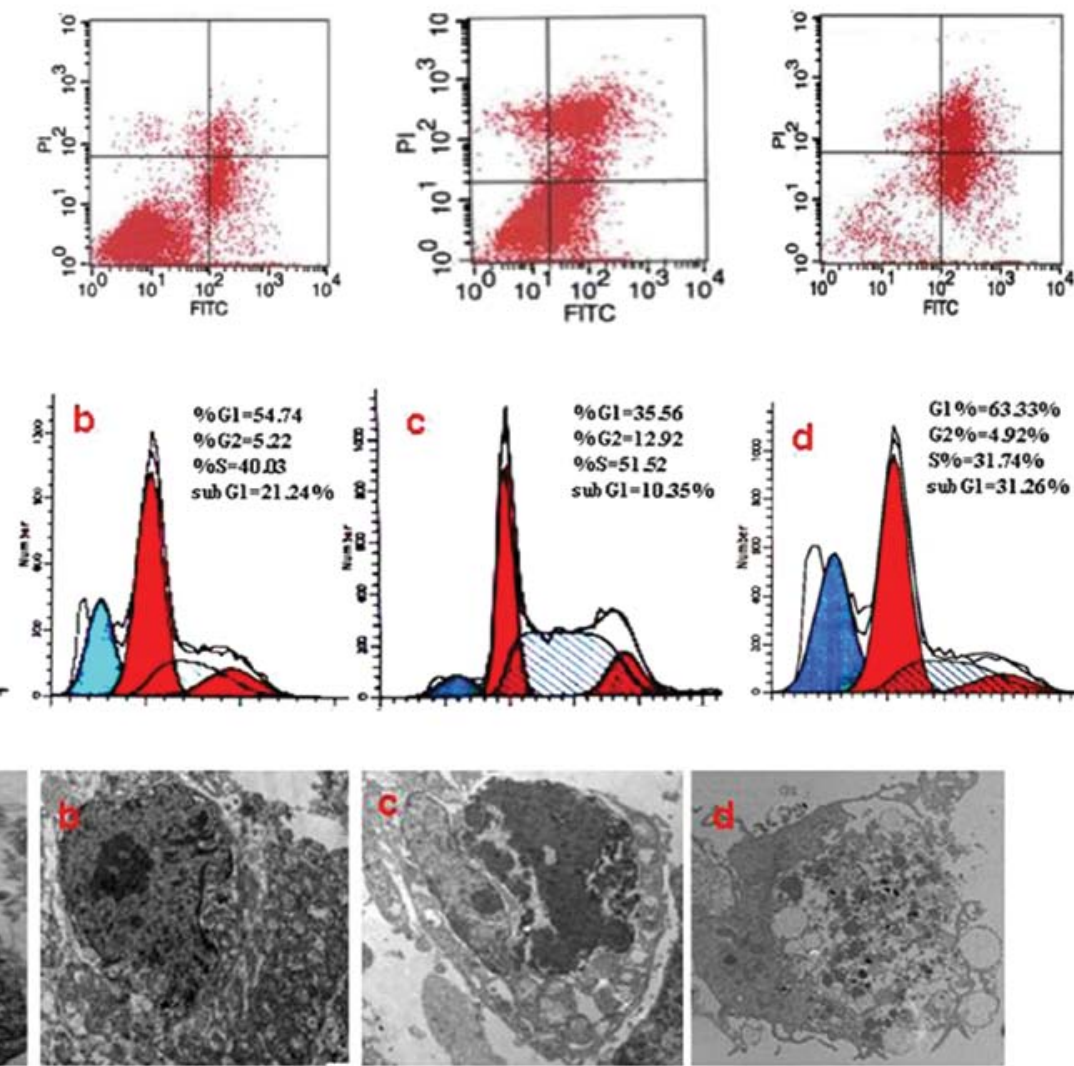

Figure 5. JB induces $\mathrm{S}$ arrest and apoptosis in vivo. (A) Flow cytometry data indicate $\mathrm{S}$ arrest in tumor tissue following treatment with JB. (B) a, Control; b, JB; c, 5-Fu; d, JB+5-Fu. Staining and Annexin V/PI dual-immunofluorescence staining revealed that JB was able to significantly increase the cells of apoptosis and necrosis. (C) There were different changes in the four groups when we observed them by transmission electron microscope. a, Control; b, JB; c, 5-Fu; d, JB+5-Fu.
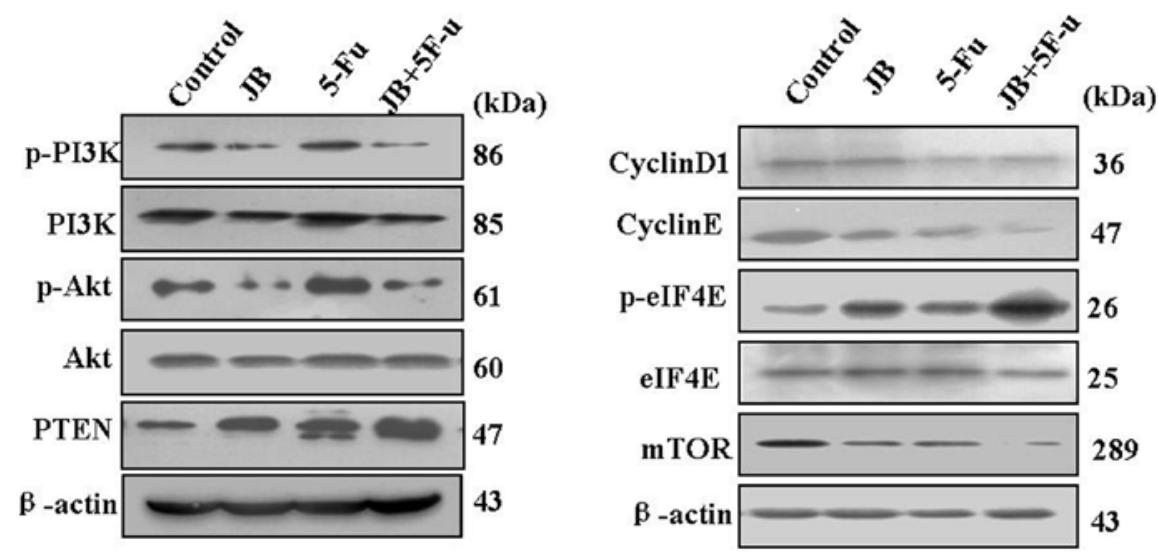

Figure 6. Effect of JB on the PI3K/Akt/mTOR signal pathway in tumor tissues. Proteins were extracted, then cyclinD1, cyclinE, p-PI3K, p-Akt, PTEN, mTOR and p-eIF4E expressions were determined by western blot analysis. The results showed downregulation of cyclinD1, cyclinE, mTOR, p-PI3K and p-Akt, and upregulation of PTEN and p-eIF4E. Densitometric values of protein bands were normalized to those of $\beta$-actin. The expression of PI3K, Akt and eIF4E had no significance in any of the groups.

Effect on the PI3K/Akt/mTOR signaling pathway in tumor tissue. The expression of cyclinD1, cyclinE, mTOR, p-PI3K and p-Akt in the the tumor tissues of the JB group was significantly lower than that in the control group $(\mathrm{P}<0.05)$ (Fig. 6). This is in contrast to the upregulation of PTEN and p-eIF4E compared to that in the control group $(\mathrm{P}<0.05)$. Immunohistochemical staining of p-PI3K, p-Akt, PTEN, mTOR showed the expression of proteins in tumor tissues. By staining the PTEN of the
JB group, its staining intensity became gradually stronger than in the control group $(\mathrm{P}<0.05)$, indicating high cell proliferation activity. Staining intensity of p-PI3K, mTOR and p-Akt was significantly weaker in nude mice treated with JB compared to the control group $(\mathrm{P}<0.01)$ (Fig. 7). These results reveal that JB was able to downregulate the expression of the p-PI3K, mTOR and $\mathrm{p}$-Akt proteins whereas it upregulated the expression of the PTEN protein. 


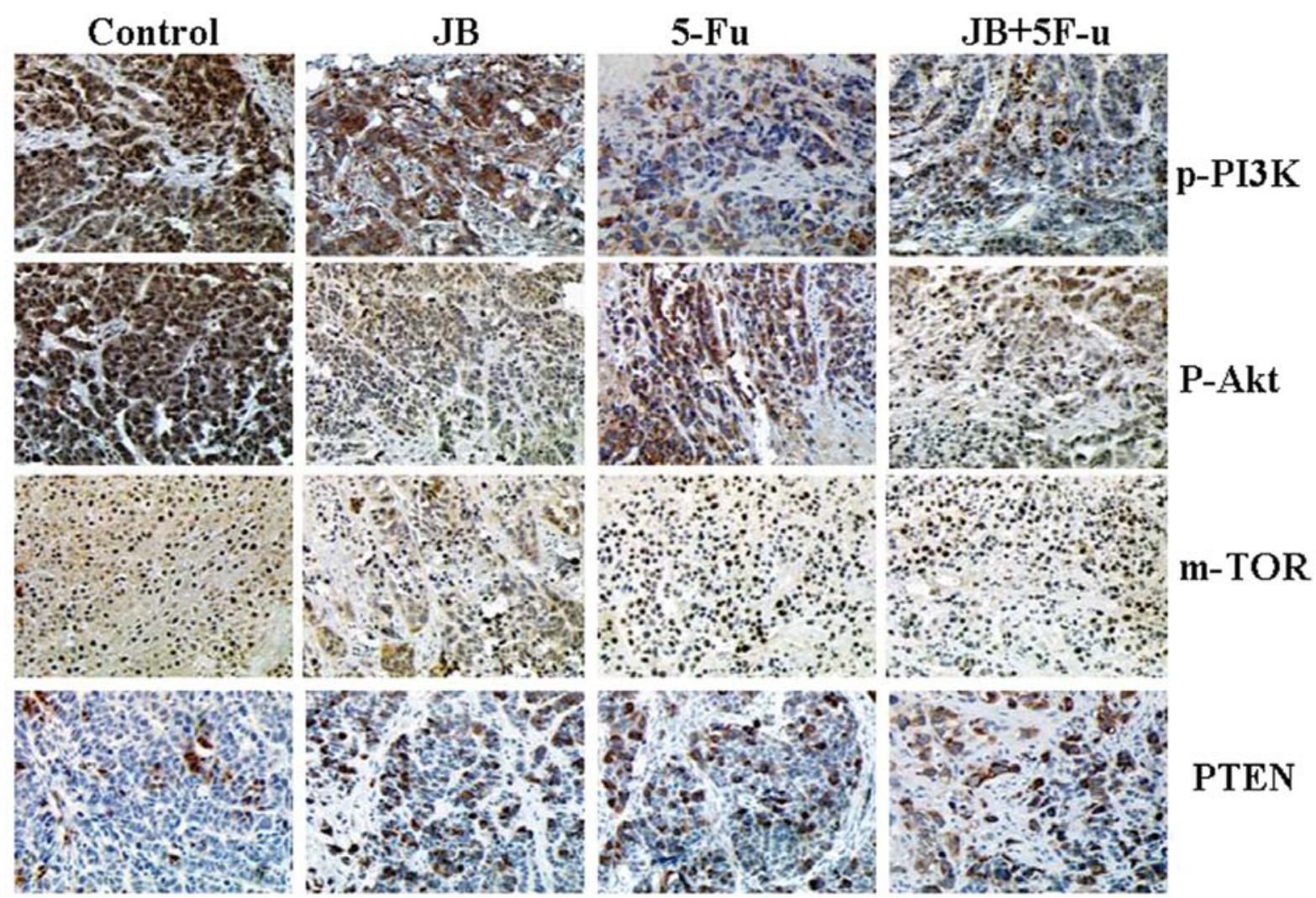

Figure 7. Immunohistochemical staining of p-PI3K, p-Akt, PTEN and mTOR showed that positive cells labeled brown in the cytoplasm of tumor tissues. PTEN staining intensity became stronger in the JB group than in the control group $(\mathrm{P}<0.01)$. The staining intensity of p-PI3K, mTOR, p-Akt were significantly weaker in tumor-bearing mice in the JB-treated group compared to the control group $(\mathrm{P}<0.01)$ (original magnification, $\mathrm{x} 200)$.

\section{Discussion}

JB was employed in this study to investigate its mechanism to induce apoptosis in vitro and in vivo. The results demonstrated that jolkinolide B (JB) inhibited the PI3K/Akt/ mTOR signaling pathway leading to apoptotic cell death. The dried roots of Euphorbia fischeriana Steud have a long history of being used as folk medicine, and antitumorigenic constituents, such as the diterpenoid compound 17-acetoxyjokinolide B and JB, have been identified (5). However, the molecular mechanism of JB remains largely unknown. In the present study, the mechanism of apoptosis was examined by the proliferation of MCF-7 cells and the tumor growth curve, cell cycle, cell apoptosis, cell morphology and animal experiments. We found that the Akt-dependent signaling pathway could be involved in the effect of JB on nude mice.

Cell cycle was determined by flow cytometry in vivo and in vitro. The results were consistent. MCF-7 cells were arrested in the cell cycle at $\mathrm{S}$ phase in vitro and in vivo. However, the tumor tissue had cellular debris and necrotic tissue making the animal experimentation difficult.

Transmission electron microscopy (TEM) showed that JB markedly induced apoptosis in vivo and in vitro. The control group cells grew significantly. The JB and the 5-Fu group cells kept their membrane integrity and cytoplasm condensed. Cells became pyknotic and small, nuclear chromatin was dense with lumps of different sizes, located mainly in the nuclear membrane. Nuclear DNA of apoptotic cells displayed ladder bands characteristic of internucleosomal DNA fragmentation and apoptosis.

The PI3K/Akt signaling pathway has been reported to play an essential role in various cellular processes including apoptosis, survival, proliferation and differentiation $(6,7)$. Activated PI3K initiates the activation of the downstream Akt kinase. Moreover, phosphorylated Akt could facilitate cell survival and proliferation and regulate various signaling pathways (8-10). It has been shown that the activation of PI3K and Akt could inhibit autophagy. Yuan et al (12) confirmed that there is a close relationship between the excessive expression and activation of Akt kinase and the malignant biological behavior of ovarian cancer $(11,12)$. The PI3K/Akt signaling pathway has been closely related to the occurrence of human malignant tumors, such as endometrial cancer and non-small cell lung cancer $(13,14)$. JB treatment of MDA-MB-231 cells decreased the expression of the PI3K p85 subunit and the phosphorylated Akt in a concentration-dependent manner (4). Disregulation of the PI3K/AKT pathway leads to unchecked cellular growth and proliferation.

Due to the complexity of this signaling cascade, especially as applied to the regulation of the mammalian target of rapamycin (mTOR), the activation of PI3K/Akt may be through the TSC1/2 complex.

The eIF-4E suppresses molecules with protein 1 (4E-BP1) and ribosomal protein $\mathrm{P} 70 \mathrm{~S} 6 \mathrm{~K}$ (16-18). 4E-BP1 phosphorylation is reduced after treatment with EIF-4E (19). PI3K/ Akt signaling pathways may adjust inhibition the PTEN 
(20). PTEN can make PI-3, 4, 5-P3 to phosphoric acid and thus inhibits Akt activation, restraining the cyclin E-CDK2 complex, making the cell block in the G1 phase (21). Tumorsuppressor gene mutations or lack of PTEN will lead to PI-3, 4, 5-P3 phosphorylation and Akt activation.

In conclusion, results of the MTT assay, flow cytometry and TEM analysis showed that JB was able to inhibit the growth of MCF-7 cells and induce apoptosis. JB significantly decreased tumor volume and weight in nude mice. In addition, tumor tissue treatment with JB was able to induce downregulation of cyclinD1, cyclinE, mTOR, p-PI3K and p-Akt, and upregulation of PTEN and p-eIF4E. JB-induced apoptosis of MCF-7 cells occurs through the inhibition of the PI3K/Akt/ mTOR signaling pathway. This appears to be a key mechanism behind the JB-induced suppression of the breast cancer cell growth in animal models. Therefore, JB may serve as a novel promising compound in cancer therapy.

\section{Acknowledgements}

This study was supported by the National Natural Science Foundation of China (No. 30973902), the Province Natural Science Foundation of Hei Long Jiang (No. D200929) and the Science and Technology Bureau mandatory subject of Qiqihar (SF-08001).

\section{References}

1. Wang YB and Huang R: Diterpenoids from the roots of Euphorbia fischeriana. J Nat Prod 69: 967-970, 2006.

2. Liu WK and Ho JC: Jolkinolide B induces neuroendocrine differentiation of human prostate $\mathrm{LNCaP}$ cancer cell line. Biochem Pharmacol 63: 951-957, 2002.

3. Luo $\mathrm{H}$ and Wang $\mathrm{A}$ : Induction of apoptosis in $\mathrm{K} 562$ cells by jolkinolide B. Can J Physiol Pharmacol 84: 959-965, 2006.

4. Lin Y, Cui H, Xu H, Yue L, Xu H, Jiang L and Liu J: Jolkinolide B induces apoptosis in MDA-MB-231 cells through inhibition of the PI3K/Akt signaling pathway. Oncol Rep 27: 1976-1980, 2012.

5. Wang HB and Chu WJ: Diterpenoids from the roots of Euphorbia fischeriana. J Asian Nat Prod Res 12: 1038-1043, 2010.
6. Osaki M and Oshimura M: PI3K-Akt pathway: its functions and alterations in human cancer. Apoptosis 9: 667-676, 2004.

7. Franke TF: PI3K/Akt: getting it right matters. Oncogene 27: 6473-6488, 2008.

8. Geering B and Cutillas PR: Regulation of class IA PI3Ks: is there a role for monomeric PI3K subunits. Biochem Soc Trans 35: 199-203, 2007.

9. Sussman M: 'AKT'ing lessons for stem cells: regulation of cardiac myocyte and progenitor cell proliferation. Trends Cardiovasc Med 17: 235-240, 2007.

10. Tsurutani J and Steinberg SM: Prognostic significance of clinical factors and Akt activation in patients with bronchioloalveolar carcinoma. Lung Cancer 55: 115-121, 2007.

11. Wu YT and Tan HL: Activation of the PI3K-Akt-mTOR signaling pathway promotes necrotic cell death via suppression of autophagy. Autophagy 5: 824-834, 2009.

12. Yuan ZQ and Sun M: Frequent activation of AKT2 and induction of apoptosis by inhibition of phosphoinositide-3-OH kinase/Akt pathway in human ovarian cancer. Oncogene 19: 2324-2330, 2000.

13. Achiwa $\mathrm{Y}$ and Haseqawa K: Regulation of phosphatidylinositol 3-kinase-Akt and the mitogen-activated protein kinase pathways by ursolic acid in human endometrial cancer cells. Biosci Biotechnol Biochem 71: 31-37, 2007.

14. Tang JM and He QY: Phosphorylated Akt overexpression and loss of PTEN expression in non-small cell lung cancer confers poor prognosis. Lung Cancer 51: 181-191, 2006.

15. Coffey JC and Wang JH: Phosphoinositide 3 kinase accelerates postoperative tumor growth by inhibiting apoptosis and enhancing resistance to chemotherapy-induced apoptosis. Novel role for an old enemy. J Biol Chem 280: 20968-20977, 2005.

16. Huang S and Houghton PJ: Targeting mTOR signaling for cancer therapy. Curr Opin Pharmacol 3: 371-377, 2003.

17. Zhou X and Tan M: Activation of the Akt/mammalian target of Rapamycin/4E-BP1 pathway by ErbB2 overexpression predicts tumor progression in breast cancers. Clin Cancer Res 10: 6779-6788, 2004.

18. Asnaghi L, Bruno P, Priulla M, et al: mTOR: a protein kinase switching between life and death. Pharmacol Res 50: 545-549, 2004.

19. Coleman LJ and Peter MB: Combined analysis of eIF4E and 4E-binding protein expression predicts breast cancer survival and estimates eIF4E activity. Br J Cancer 100: 1393-1399, 2009.

20. Bonifazi $P$ and D'Angelo C: Intranasally delivered siRNA targeting $\mathrm{PI} 3 \mathrm{~K} / \mathrm{Akt} / \mathrm{mTOR}$ inflammatory pathways protects from aspergillosis. Mucosal Immunol 3: 193-206, 2010.

21. Madlener S and Saiko P: Multifactorial anticancer effects of digalloyl-resveratrol encompass apoptosis, cell-cycle arrest, and inhibition of lymph endothelial gap formation in vitro. $\mathrm{Br} \mathbf{J}$ Cancer 102: 1361-1370. 2010. 